\title{
UNA REVOLUCIÓN EN MARCHA
}

DOI: https://doi.org/10.52039/seminarios.v60i211.218

RAFAEL NAVARRO-VALLS*

Recién elegido el Papa Francisco, me permití enunciar los principales desafíos con los que, en mi opinión, se enfrentaba. La verdadera reforma que tendría que afrontar, observé, no era la de la Curia, sino la de la preparación intelectual, humana y espiritual de los 721935 religiosos y 412236 sacerdotes extendidos por el mundo, incluidos obispos y cardenales. Una tarea directamente conectada con la eficacia de los mayores responsables en la Iglesia en la difusión del mensaje cristiano.

\section{UNA NUEVA REFORMA}

En lo que se me alcanza, a este millón de sacerdotes y religiosos va dirigido, primordialmente, este programático documento del Papa Francisco, Evangelii Gaudium (La alegría del Evangelio), que anuncia una verdadera reforma a todos los niveles. Conviene no olvidar que, en la Iglesia, las reformas que han triunfado han suscitado al principio resistencias. La expresión Ecclesia semper reformanda indica que la Iglesia exige continuadamente un proceso de adaptación a la voluntad de Dios. Un proceso que la naturaleza caída suele perturbar. En esa línea se movieron las reformas de Cluny, Trento o las impulsadas por Pío V, Pío X, Bernardo de Claraval , Francisco de Asís o Teresa de Jesús. Ante ellas, hubo una mayor o menor resistencia inicial por otros miembros de la Iglesia, «instalados», es decir, aburguesados 0 , al menos, desorientados.

Sin embargo, no conviene confundir el sentido de la «reforma» en la visión protestante y en la católica. Para la primera, la Iglesia habría sido infiel a sus principios y por eso requiere una especie de refundación. Para los católicos, el proceso de reforma en la Iglesia se refiere primordialmente, «tanto en la cabeza como en los miembros», a una especie de «conversión» que rectifique el rumbo desnortado que las coordenadas de tiempo y espacio puedan haber introducido. Retomando la clásica expresión de Juan Pablo II -coincido con John Allen- el sueño de Francisco en este documento programático sería la de «una Iglesia que respire con los dos pulmones de la misión y de la justicia, uniendo la preocupación por la pobreza espiritual y material».

* Rafael Navarro-Valls es catedrático, académico y autor de Entre la Casa Blanca y el Vaticano. El presente artículo fue originalmente publicado por Zenit el 4 de diciembre de 2013. 


\section{UNA ECONOMÍA QUE MATA}

Naturalmente, la vertiente de esa «conversión» que más ha llamado la atención en los medios ha sido la dimensión social del mensaje evangélico, es decir, el pulmón de la justicia y la lucha contra la pobreza.

$Y$ es natural que así haya sido, pues en esa contienda el primer adversario para Francisco es la «economía que mata», una frase fuerte que apunta-siempre según el Pontífice- a esa economía que confía en las fuerzas ciegas y la mano invisible del mercado, que recurre a remedios que son «un nuevo veneno, como cuando se pretende aumentar la productividad reduciendo el mercado laboral y creando así nuevos excluidos». ¿Supone esto descalificar el libre mercado? Esta es una vieja pregunta que ya se hizo cuando Juan Pablo II o Benedicto XVI condenaron el «turbo-capitalismo», ajeno a la «solidaridad y la subsidiariedad». Si Juan Pablo Il fue un crítico del capitalismo más incisivo que Marx, pues no cayó en la ingenuidad de reducir la vida social a economía, Benedicto XVI se concentró en la crisis financiera con la intensidad de un rayo láser, insistiendo en la crisis mundial que, en su inicio, destapó la podredumbre de Maddoff y compañía. Ahora Francisco entra con nuevos requerimientos para exigir -«ya no se puede esperar más»-que se aborden «las causas estructurales de la pobreza», resolviendo «radicalmente los problemas de los pobres, renunciando a la autonomía absoluta de los mercados y de la especulación financiera, y atacando las causas estructurales de la inequidad», o sea, las disfunciones de la economía mundial.

Desde luego, esto no supone -como dicen algunos- que en el mundo empresarial «los beneficios son obscenos y las pérdidas castas». Ya se entiende que Francisco no entra en ese juego, ni aboga por un sistema de «economías angélicas», precisamente porque, según sus palabras en EG, la empresarial es una «noble tarea», ante la cual sus palabras no deben entenderse como las de un «enemigo», sino como la de un amigo-«ajeno a cualquier interés personal o ideología política»- que desea apartar de una mentalidad «individualista, indiferente y egoísta», en aquellos que la poseen. Se trata, en síntesis, de exigir una sólida responsabilidad social a los agentes económicos.

Naturalmente, también la «pobreza espiritual», la ausencia de valores, el aburguesamiento, el apartamiento de Dios, etc. es objeto de atención para Francisco, al ser la evangelización el centro del documento. Tal vez por seguir en este punto la doctrina habitual ha despertado menos interés, pero nótese que la lucha contra esa «pobreza espiritual» va paralela a la contienda contra la corporal.

\section{DESCENTRALIZACIÓN}

Al enfrentarme con un texto jurídico, recuerdo dos consejos de un viejo colega. El primero: para entender bien una sentencia importante hay que leer con detenimiento los votos concurrentes, pues amplían el sentido del fallo. El segundo, 
cuando leas un documento científico detente con especial cuidado en sus notas, pues descubren las líneas de fuerza que han preparado el camino del autor.

Si fijamos nuestra atención en el texto de la EG, lo primero que resalta, aparte de las referencias bíblicas y magisteriales, es el desusado número de notas dedicadas a los documentos de las Conferencias Episcopales de Latinoamérica, India, Estados Unidos, Francia, Brasil, Filipinas o el Congo. Y naturalmente a los pronunciamientos de Puebla y Aparecida, así como otras post-sinodales: Ecclesia in Africa, in Asia, in Oceania, in America, in Europa y en Oriente Medio.

Esto explica una tensión presente en todo el documento. La que se se ha llamado «tensión entre diferencia y unidad», o si se quiere entre "centralización y descentralización». Así lo expresa el Papa: «La diversidad cultural no amenaza la unidad de la Iglesia» (n. 117). A la vez, implica al papado en la reforma en marcha, pues el «papado y las estructuras de la Iglesia universal necesitan escuchar la llamada a una conversión» sabiendo que «una excesiva centralización, más que ayudar, complica la vida de la Iglesia» (n. 32). De ahí la continua remisión de EG a las enseñanzas de la Iglesias locales o las Conferencias Episcopales.

\section{IR A LOS FUNDAMENTOS}

Una de las cosas que dejó algo perplejo a los vaticanistas fue que el Papa Francisco no puso especial acento en aquellas cuestiones que Benedicto XVI denominó «no negociables»: vida, matrimonio, educación. En algunos fieles esa perplejidad derivó en cierto desencanto: como si esas temáticas carecieran de importancia, cuando había sido el punto focal de muchos esfuerzos pastorales de los obispos y de acción social política de muchos laicos.

Esa conclusión no es exacta. En la EG el papa insiste en el valor de la defensa de la vida del no nacido (213), en no constituir el matrimonio de cualquier forma (66), en el valor de la educación y la posición de los padres en ella (132). La mejor explicación de que, a pesar de esto, esas cuestiones no se pongan en la vanguardia de la acción probablemente es esta del periodista Guido Horst: «Francisco sabe como cualquier pastor que cuando se ha apagado la fe, no tiene ningún sentido azotar al caballo por detrás, y comenzar la nueva evangelización por la doctrina moral de la Iglesia, sino que hay que poner de nuevo los fundamentos: la fe en Dios, el conocimiento del amor y la misericordia del Padre y la obra salvadora de Jesucristo».

Efectivamente, a esos tres grandes temas apunta como una flecha este documento programático del Papa Francisco. 